\title{
Using Blood Donor-Derived ABO and RhD Blood Groups Helps to Detect Wrong Blood in Tube Errors in Recipients
}

\author{
Christoffer Dellgren ${ }^{a} \quad$ Mark H. Yazer ${ }^{b} \quad$ Ulrik Sprogøe ${ }^{a}$ \\ a Department of Clinical Immunology, Odense University Hospital, Odense, Denmark; \\ b The Institute for Transfusion Medicine, Department of Pathology, University of Pittsburgh, Pittsburg, PA, USA
}

\section{Keywords}

ABO blood group - Blood transfusion .

Data management system - Donors - Transfusion risks . Error

\section{Summary}

Background: Comparing the $\mathrm{ABO}$ and $\mathrm{RhD}$ group of a recipient's current pre-transfusion sample against their historical group is an important means of detecting wrong blood in tube (WBIT) errors. This study investigated the utility of using the donor $A B O$ and RhD group as the historical check for recipients. Methods: A single database stores serological information on blood donors, pregnant women, and patients throughout southern Denmark. A donor ABO and RhD group can be the historical blood group should that donor later require a transfusion. This database was searched to determine how often the $A B O$ and $R h D$ group on a recipient's current pre-transfusion sample was discrepant with their historical donor-derived blood group. Results: During about 21 years, $A B O$ and $\mathrm{RhD}$ groupings were performed on 76,455 blood donors and on 424,697 patients. There were $13,630 / 424,697$ (3.2\%) patients who had their donor-derived $A B O$ and $\mathrm{RhD}$ group used as the historical comparison with the current sample; $6 / 13,630(0.04 \%)$ of the current pre-transfusion samples on these patients were discrepant with the donor-derived historical group because of WBIT errors. Seven other discrepancies with the donor-derived blood group were also found. Conclusion: Accessing the donor-derived $A B O$ and $\mathrm{RhD}$ group can be an important safeguard against WBIT-mediated mistransfusions.

(C) 2017 S. Karger GmbH, Freiburg

\section{Introduction}

Establishing the recipient's $\mathrm{ABO}$ blood group is of paramount importance in ensuring a safe transfusion. The $\mathrm{AABB}$ requires that the results of a recipient's current $\mathrm{ABO}$ grouping be checked against any historical groupings on file at the transfusion service. Having access to a potential recipient's historical ABO grouping is an important safety measure as discrepancies between the two groupings can be caused by major collection errors where the blood in the tube does not come from the patient whose name is on the identification label. Sometimes known as wrong blood in tube (WBIT) [1], these errors require further investigation and resolution before group-specific red blood cells (RBCs) can be issued. In a review of $\mathrm{ABO}$ discrepancies in a large, multihospital centralized transfusion service (CTS) in the USA [2], 16 major collection errors where the current $\mathrm{ABO}$ group did not match that on file were discovered; in 6 of these errors, the historical ABO group had been performed at a different hospital within the CTS network compared to where the grouping on the current sample was performed. Similarly, in a regional transfusion service in France, where all patients admitted to hospital undergo $\mathrm{ABO}$ grouping as a means of improving patient identification, 19 incompatible transfusions were interceded as a result of having access to a regional centralized database of recipient blood groups [3].

For patients who do not have a historical $\mathrm{ABO}$ group on file, there are several ways of ensuring their serological safety during pre-transfusion testing. One method involves having at least two different blood bank technologists perform the $\mathrm{ABO}$ grouping on the same sample from the recipient. If both of their groupings match, the ABO group of the recipient is said to be 'confirmed'. However, this method only confirms the ABO group of the blood in the tube; it cannot confirm that a WBIT error had not been made. A more reliable method for ensuring the accuracy of the $\mathrm{ABO}$ group of a patient without a historical type is to collect a second sample at some point after their first sample was collected [4].

\section{KARGER}

๑) 2017 S. Karger GmbH, Freiburg

Fax +497614520714 
Often known as a 'check type sample', having the hospital staff repeat the patient identification process in the course of drawing a second sample and comparing the $\mathrm{ABO}$ groups on both samples should help to identify WBIT errors and prevent mistransfusions. Indeed, in the 17-year experience of one large hospital, employing a check type sample policy identified 21 WBIT errors [5].

Another situation where it is important to accurately establish the $\mathrm{ABO}$ group is when testing blood donors. As a large segment of the population becomes older, people who had previously donated blood might require a transfusion. Thus, hospitals with blood donor centers could create electronic files at their hospitals containing the $\mathrm{ABO}$ group of their donors, thereby establishing a historical $\mathrm{ABO}$ group for each of their donors should they become recipients. This report describes the use of $\mathrm{ABO}$ and $\mathrm{RhD}$ groups obtained at the time of donation as the recipients' historical grouping in a regional transfusion service and hospital network in southern Denmark.

\section{Material and Methods}

Data were collected from the South Danish Transfusion Service database (SDTD, ProSang version 7.1; Databyrån, Stockholm, Sweden). The SDTD contains serological information on blood donors as well as serological information on all patients (including the results of routinely performed immunohematological testing on pregnant women) on whom pre-transfusion testing had been performed in the hospitals in the Region of Southern Denmark since 1995 [6]. This region has a population of 1.2 million inhabitants. All information in the SDTD is stored by each person's unique Danish personal identification number (PIN, described in [7]). For this study, data was extracted from the SDTD for people who had donated blood and/or were seen as patients on the island of Funen in the Region of Southern Denmark. Funen has a population of approximately 460,000 inhabitants, historically 9 hospitals (now consolidated into 4; during the consolidation period the workflow with respect to ProSang data entry and utilization continued without interruption), and has been contributing data to the SDTD on patients in this area since the inception of the database.

The SDTD is accessed in the transfusion service laboratories at the 4 hospitals in Funen when issuing blood products as it contains all of the relevant historical serological information on the intended recipient. It is a requirement at the hospitals in Funen that each recipient must have two independently collected samples that demonstrate the identical $\mathrm{ABO}$ and $\mathrm{RhD}$ groups before cross-matched RBCs can be issued [6]. One of these samples can be a historical ABO group that had been entered into the SDTD before the current transfusion episode. Because the SDTD contains both donor and recipient serological information, it has been configured to use the $\mathrm{ABO}$ and $\mathrm{RhD}$ group that was determined at the time of blood donation as the historical grouping should that donor require a transfusion. Of note, in this region people who visit a blood collection center have their $\mathrm{ABO}$ and $\mathrm{RhD}$ groups determined on their first visit, but they do not actually make a blood donation until they return for a second visit; as such, some potential donors are lost to attrition even though their $\mathrm{ABO}$ and $\mathrm{RhD}$ groups are recorded in the SDTD. Herein, the term 'blood donor' will be used to refer to anyone who had an $\mathrm{ABO}$ and $\mathrm{RhD}$ group determination performed at a blood center regardless of whether they actually returned to make a donation. As a result, recipients who have been blood donors only need to have one additional $\mathrm{ABO}$ and $\mathrm{RhD}$ group determined at the time of transfusion before cross-matched RBCs can be issued.

Data Collection for this Study

Complete lists of unique blood donors and patients who had an $\mathrm{ABO}$ and $\mathrm{RhD}$ group determination performed in Funen between June 7, 1995 and May 3, 2016 were generated, and their records were coupled by using their unique Danish PIN [7].

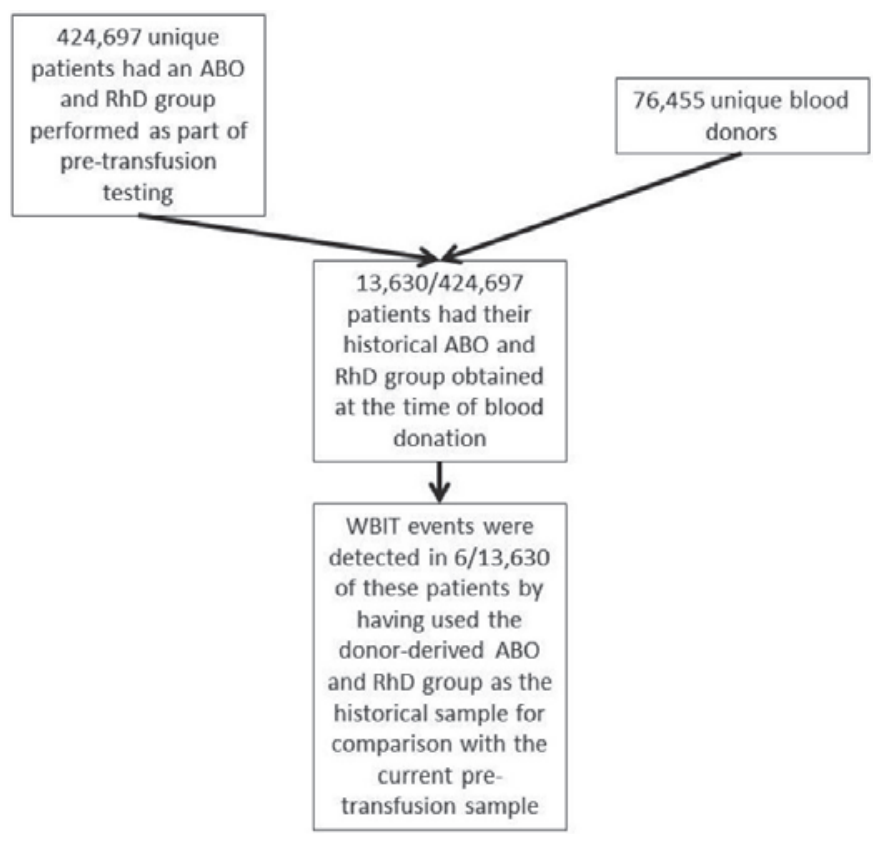

Fig. 1. Flow chart of the study design. The study spanned the time period of June 7, 1995 and May 3, 2016, and involved patients and blood donors on the island of Funen in southern Denmark.

The SDTD manages test results such that when an $\mathrm{ABO}$ and $\mathrm{RhD}$ group result is entered on a potential recipient that is discrepant with their historical grouping, the current test result becomes 'inactivated'. This inactivation occurs regardless of whether the historical group was the one entered when the recipient donated blood or if it was from a subsequent sample collected in hospital. Therefore, situations suggestive of a WBIT event in recipients were identified in the SDTD by reviewing the inactivated test records and looking specifically for situations where the recipient's current $\mathrm{ABO}$ and $\mathrm{RhD}$ group result was inactivated because of a discrepancy with the donor-derived $\mathrm{ABO}$ and $\mathrm{RhD}$ group. When these situations were encountered, the nature of the discrepancy and how it was resolved was further investigated. A WBIT error was defined as one where either the recipient's current $\mathrm{ABO}$ or $\mathrm{RhD}$ group did not match their $\mathrm{ABO}$ or $\mathrm{RhD}$ group that was obtained at the time of blood donation without another explanation.

Ethics

The data collection protocol for this study was approved by the Danish Patient Safety Authority.

\section{Results}

During the approximately 21-year study period, 123,575 ABO and $\mathrm{RhD}$ groupings on 76,455 unique donors and 1,364,588 $\mathrm{ABO}$ and $\mathrm{RhD}$ groupings on 424,697 unique patients were identified in the SDTD database. In total the study comprised 1,488,162 analyses from 483,153 unique individuals. The $\mathrm{ABO}$ and $\mathrm{RhD}$ group that was obtained at the time of blood donation provided the historical check on the recipient's current sample in $13,630 / 424,697$ (3.2\%) patients. In 6/13,630 (0.04\%) of these patients, the result of the current pre-transfusion $\mathrm{ABO}$ and $\mathrm{RhD}$ group was discrepant with the historical donor-derived $\mathrm{ABO}$ and $\mathrm{RhD}$ group (fig. 1). All of these errors were resolved by obtaining additional samples for 
Table 1. $\mathrm{ABO}$ and $\mathrm{RhD}$ discrepancies detected in blood product recipients due to having a historical blood group that was obtained at the time of blood donation in a regional transfusion database

\begin{tabular}{ll}
$\begin{array}{l}\text { Cause of discrepancy between current } \\
\text { and donor-derived } \mathrm{ABO} \text { and RhD group }\end{array}$ & $\begin{array}{l}\text { Number of discrepancies } \\
\text { detected }\end{array}$ \\
\hline Weak D variant & 6 \\
WBIT & 6 \\
Stem cell transplantation & 1 \\
\hline WBIT = Wrong blood in tube. & \\
\hline
\end{tabular}

testing from the patient, which were all subsequently found to be concordant with the donor-derived $\mathrm{ABO}$ and $\mathrm{RhD}$ group, indicating that a WBIT error had occurred in the process of obtaining the current blood sample. The 6 WBIT errors were spaced evenly over time (occurring in 1999, 2002, 2003, 2009, 2011 and 2013), and the majority of these, 5/6 (83\%), were identified because of an $\mathrm{ABO}$ discrepancy between the donor-derived group and that of the current sample. The 6th WBIT case involved a person who typed strongly $\mathrm{RhD}$-positive in their donor-derived grouping, but as a recipient initially typed $\mathrm{RhD}$-negative. A second sample obtained on this recipient revealed a strong positive $\mathrm{RhD}$ grouping, which had been found on their original grouping as a blood donor, indicating that the sample that typed as $\mathrm{RhD}$-negative was actually the result of a WBIT error.

In addition to the 6 WBIT miscollection errors, there were 7 other $\mathrm{ABO}$ or $\mathrm{RhD}$ discrepancies that were discovered by having the donor-obtained $\mathrm{ABO}$ and $\mathrm{RhD}$ group in the recipient's electronic file (table 1). These other discrepancies included 5 patients who were found to be $\mathrm{RhD}$-positive at the time of blood donation but tested $\mathrm{RhD}$-negative when they were grouped as recipients (confirmed on repeat testing on additional samples obtained at the time, these recipients underwent $\mathrm{ABO}$ and $\mathrm{RhD}$ grouping). A 6th patient also typed $\mathrm{RhD}$-positive at the time of donation but typed weakly $\mathrm{RhD}$-positive as a recipient. Three of these people were subsequently shown to be DVI. One other patient had undergone stem cell transplantation from a donor with a different $\mathrm{ABO}$ group than their native type between the time he donated blood and the time he underwent $\mathrm{ABO}$ and $\mathrm{RhD}$ grouping as a recipient, which created a discrepancy between his historical and current blood groups.

\section{Discussion}

Double checking a recipient's $\mathrm{ABO}$ group is an important safety measure for detecting WBIT errors and preventing mistransfusions. This study has demonstrated the utility of using the donor's $\mathrm{ABO}$ group as a historical check on the current pre-transfusion sample should that donor require a transfusion. As an accurate $\mathrm{ABO}$ group is always obtained during the process of preparing an $\mathrm{RBC}$ unit at the blood center, this information essentially exists for all blood donors and would provide an added safety benefit of do- nating blood. Although only a small fraction of the donors who became recipients had a WBIT error detected by having their donorderived $\mathrm{ABO}$ group available for a historical control, no additional cost was incurred by using the donor-derived $\mathrm{ABO}$ group as a recipient $\mathrm{ABO}$ verification, and 6 potentially $\mathrm{ABO}$-incompatible $\mathrm{RBC}$ transfusions, with all their attendant potential for morbidity and mortality, were successfully avoided. In addition, the presence of a historical ABO group in the SDTD negated the need to draw a confirmatory sample from thousands of recipients thereby reducing both costs to the hospital and patient discomfort.

In addition to detecting $\mathrm{ABO}$ discrepancies, having the donorderived $\mathrm{ABO}$ group available for recipients also permitted the identification of several other blood grouping peculiarities. There were several $\mathrm{RhD}$ typing discrepancies between the donor-derived $\mathrm{RhD}$ group and the current sample. In the majority of cases, the discrepancies were explicable by the differences in the types of reagents used for grouping donors compared to those used for recipients, i.e., the weak D test is performed on donors, but not on recipients, hence the detection of donors - but not of recipients with a weak D phenotype at the time of donation. In other situations, the discrepancies were likely caused by the evolution and changes in the $\mathrm{RhD}$ typing methods and reagents that occurred over the 21 years in which the SDTD has been in use.

This study has several limitations. The rate of WBIT in this study does not necessarily reflect the overall rate of WBIT at the hospitals in Funen. Based on the identified WBIT rate of $0.04 \%$ and an estimated $27 \%$ of samples from any two patients in Funen (patient $\mathrm{ABO}$ and RhD frequencies: O 42\%; A 43\%; B 11\%; AB 4\% and $\mathrm{RhD} 84 \%$ ) by chance having the same $\mathrm{ABO}$ and $\mathrm{RhD}$ groups, the actual WBIT rate in Funen is approximately $0.06 \%$, because some WBIT miscollections will have come from patients who are $\mathrm{ABO}$ - and $\mathrm{RhD}$-identical to the intended recipient. Thus, these miscollections could not be identified as WBIT errors [4]. However, this is a limitation common to all check type samples unless extended RBC phenotyping or genotyping is concomitantly performed, which would not likely be the standard of care at most institutions. Lastly, if incorrect data is entered into the database, its safety utility is reduced. The vast majority of results are directly entered into the SDTD by the automated instruments that perform the testing, without requiring human intervention. For the few tests that are manually entered into the database, great care is taken to ensure that accurate information is being entered (e.g., double data entry is mandatory in ProSang). All test results are always electronically compared to any previous test results that had already been entered in the database as a means of detecting errors.

In the Region of Southern Denmark, the SDTD is accessed by using each person's unique Danish PIN when grouping blood donors and when performing pre-transfusion testing on recipients. It is thus straightforward to accurately cross over donor $\mathrm{ABO}$ groups to become historical $\mathrm{ABO}$ checks for recipients. The same ease of crossing over of $\mathrm{ABO}$ groups might also exist in hospitals elsewhere that collect their own blood donors. Having a national PIN that identifies each person is a major advantage in ensuring the fidelity between donor and recipient records. For hospitals that are 
not electronically connected to their blood center, or in countries where a national PIN is not issued, it would be a challenge to develop a data sharing mechanism between donor center and hospital that would achieve the same end while respecting all applicable privacy regulations and data protection laws. Taking advantage of donor-derived $\mathrm{ABO}$ groupings adds benefit to the donation process and can potentially prevent mistransfusions.

\section{Disclosure Statement}

The authors declare no conflict of interest.

\section{References}

1 Dzik WH, Murphy MF, Andreu G, Heddle N, Hogman C, Kekomaki R, Murphy S, Shimizu M, SmitSibinga CT: An international study of the performance of sample collection from patients. Vox Sang 2003;85: 40-47.

2 MacIvor D, Triulzi DJ, Yazer MH: Enhanced detection of blood bank sample collection errors with a centralized patient database. Transfusion 2009;49:40-43.
3 Ferrera-Tourenc V, Lassale B, Chiaroni J, Dettori I: Unreliable patient identification warrants $\mathrm{ABO}$ typing at admission to check existing records before transfusion. Transfus Clin Biol 2015;22:66-70.

4 Goodnough LT, Viele M, Fontaine MJ, Jurado C, Stone N, Quach P, Chua L, Chin ML, Scott R, Tokareva I, Tabb K, Sharek PJ: Implementation of a two-specimen requirement for verification of $\mathrm{ABO} / \mathrm{Rh}$ for blood transfusion. Transfusion 2009;49:1321-1328.
5 Figueroa PI, Ziman A, Wheeler C, Gornbein J, Monson M, Calhoun L: Nearly two decades using the check-type to prevent $\mathrm{ABO}$ incompatible transfusions: one institution's experience. Am J Clin Pathol 2006;126:422-426.

6 Georgsen J, Kristensen T: From serological to computer cross-matching in nine hospitals. Vox Sang 1998; 74(suppl 2):419-425.

7 Titlestad K, Kristensen T, Jorgensen J, Georgsen J: Monitoring transfusion practice - a computerized procedure. Transfus Med 2002;12:25-34. 